\title{
Lidil
}

Revue de linguistique et de didactique des langues

\section{Les cultures éducatives et linguistiques dans l'enseignement des langues}

BEACCo, Jean-Claude, CHISS, Jean-Louis, CICUREL, F. \& VÉRONIQUE, Daniel (dir.), 2005, Paris, PUF, 276 p.

\section{Diana-Lee Simon}

\section{OpenEdition}

1 Journals

Édition électronique

URL : http://journals.openedition.org/lidil/76

DOI : $10.4000 /$ lidil.76

ISSN : 1960-6052

Éditeur

UGA Éditions/Université Grenoble Alpes

\section{Édition imprimée}

Date de publication : 1 juin 2006

ISBN : 2-914176-14-7

ISSN : $1146-6480$

\section{Référence électronique}

Diana-Lee Simon, "Les cultures éducatives et linguistiques dans l'enseignement des langues », Lidil [En ligne], 33 | 2006, mis en ligne le 01 octobre 2007, consulté le 21 septembre 2020. URL : http:// journals.openedition.org/lidil/76 ; DOI : https://doi.org/10.4000/lidil.76

Ce document a été généré automatiquement le 21 septembre 2020.

(c) Lidil 


\section{Les cultures éducatives et linguistiques dans l'enseignement des langues}

BEACCo, Jean-Claude, CHISS, Jean-Louis, CICUREL, F. \& VÉRONIQUE, Daniel

(dir.), 2005, Paris, PUF, 276 p.

Diana-Lee Simon

Quand on ne sait pas où l'on va, qu'on sache d'où l'on

vient

Tradition orale sérère

1 Saluons cet ouvrage de référence dont les diverses contributions éclairent de manière très significative, à un moment donné de son histoire et de son évolution en cours, une didactique des langues dans toute sa complexité culturelle. Les contributions individuelles réunies ici sont à lire surtout, il me semble, dans leur résonance les unes avec les autres, dans un ensemble interactif, évolutif, en mouvement qui amplifie la centralité de la donne culturelle. Le lecteur participe alors activement à la reconstruction de l'histoire de la didactique qui traverse l'ouvrage, tout en s'introduisant dans des situations concrètes d'enseignement/apprentissage des langues dans des contextes très variés qui ouvrent des fenêtres sur une complexification culturelle progressive et inéluctable du domaine.

2 Les douze articles qui composent cet ouvrage collectif émanent de communications présentées au colloque international organisé en Sorbonne du 12 au 14 décembre 2002 et intitulé «La didactique des langues face aux cultures éducatives et linguistiques». Représentatif d'une synthèse des problématiques abordées ${ }^{1}$, il est édité conjointement par les quatre responsables et leurs équipes de recherches: DILTEC (Didactique des langues, des textes et des cultures), ERADLEC (Equipe de recherche et d'accueil en didactologie des langues et des cultures) et DELCA-SYLED (Discours d'enseignement, Langues en contact, Appropriation linguistique - Systèmes linguistiques, Enonciation, Discours) de l'université de Paris III - Sorbonne Nouvelle. 
3 Si l'évènement même du colloque provoqua la rencontre et mise en contact de cultures linguistiques, éducatives et didactiques différentes (300 participants de nombreux pays), la constitution de l'ouvrage qui regroupe une sélection des contributions issues de contextes fort différents mais hautement prégnants, contribue certainement à faire émerger une nouvelle synergie entre ces cultures, qu'elles soient étiquetées "linguistiques", " éducatives" ou "didactiques». Ces notions, qui font l'objet de définitions et qui fondent l'organisation de l'ouvrage, sont interrogées comme catégories par des transversalités sous-jacentes désorganisatrices qui surgissent au fil de la lecture des articles tant les dimensions linguistiques, culturelles et didactiques sont étroitement imbriquées.

4 Dans leur présentation, les éditeurs (Jean-Louis Chiss \& Francine Cicurel), soulignent le fait que la préoccupation centrale de l'ouvrage est bien la didactique qui sert d'axe transversal entre un pôle linguistique-langagier et un pôle éducatif-pédagogique. Il y a prise en compte de relations complexes entre trois grands domaines: les cultures éducatives et l'enseignement des langues, relation largement déterminée par les contextes dans toute leur complexité ; le champ multiforme des cultures du langage ; qui tient compte de l'organisation en stratifications complexes des savoirs des langues, des textes, des discours, des littératures ; et bien entendu le socle empirique des méthodes et pratiques d'enseignement et apprentissage des langues, dont la théorisation pourrait déboucher sur la notion de "cultures didactiques».

5 Le livre s'organise en deux parties distinctes chacun regroupant six articles: une première portant sur les cultures linguistiques, et une deuxième portant sur les cultures éducatives.

6 Une première partie intitulée "Enseignements/apprentissages des langues et cultures linguistiques ». Rappel : La notion de "cultures linguistiques » renvoie à l'idée que la conceptualisation même de l'objet de la discipline - une langue, des langues - se trouve affectée par des remaniements ayant trait à une forte contextualisation.

7 Les trois premières contributions qui prennent donc comme axe d'observation/analyse, l'objet langue, et en particulier la grammaire, dans sa dimension historique tout à fait éclairante, mettent en évidence néanmoins le poids indéniable des cultures (sociales et) éducatives qui les sous-tend. Dans une perspective humaniste, Anne Godard montre comment le latin, enseigné comme langue vivante orale au xvie siècle et en particulier à travers les Colloques d'Erasme - se confond avec un modèle culturel en proposant aux enfants un apprentissage de formules de conversation, celles-ci s'inscrivant dans des considérations morales et religieuses de l'époque. Cette empreinte culturelle est marquante également dans l'analyse historique évolutive que propose Henri Besse de la didactique du début du xvile siècle en référence en particulier à la grammatisation des langues vulgaires. En remontant aux Tropes de Comenius, 1628, il montre comment l'ancrage moral et religieux de l'époque explique le choix didactique de proposer à l'apprentissage le sens propre et non pas le sens figuré des mots. Il argumente en faveur de la restitution de la "culture grammaticale» comme composante de la langue française proposée à l'apprentissage en soulignant l'importance d'aider les élèves à distinguer sens propre et sens figuré. Ensuite vient une analyse contrastive (Peter Lauwers) à partir de deux traditions grammaticales (française et allemande), qui fait émerger des divergences d'optique sur un même objet - le français contemporain en l'occurrence - mais qui s'expliquent par leur ancrage dans deux traditions ou «cultures" grammaticales qu'il entend comme «habitudes ayant trait à la 
modélisation de la description grammaticale » et non comme un ensemble de pratiques liées à l'enseignement de la grammaire. C'est ainsi qu'il met en évidence la spécificité de la tradition grammaticale française, fortement attachée à une approche ascendante et catégorielle de la syntaxe.

8 La prégnance des dimensions culturelles se renforce davantage encore dans les trois contributions suivantes qui rendent le lecteur complice de situations de classe : où la question des cultures linguistiques est abordée à partir d'un travail métalinguistique en milieu formel d'apprentissage dans trois contextes d'enseignement/apprentissage fort différents. Les représentations métalinguistiques d'enseignants et d'apprenants sont ici révélatrices du poids sous-jacent des différentes cultures éducatives qui semblent les façonner.

9 Si l'enseignant (non natif) de japonais (Dominique Klingler) se trouve dérouté dans son travail d'explicitation métalinguistique d'un élément de la langue japonaise (desu), les apprenants français pour leur part, se frottent à une difficulté liée au décalage entre leurs représentations métalinguistique - issues de leur grammaire scolaire et les explicitations proposées par l'enseignant sur une catégorie grammaticale n'ayant pas d'équivalent dans leur langue. Ce «malentendu » d'ordre culturel, qui se traduit par un questionnement métalinguistique intensif en direction de l'enseignant repose sur une mise en confrontation implicite du fonctionnement de deux langues éloignées.

La question de l'enseignement des disciplines non linguistiques pose de manière aigüe le problème de l'intégration des dimensions langue, savoir et culture et leurs rapports. L'article suivant (Anne-Claude Berthoud, Laurent Gajo, Cécilia Serra), consacré à une analyse des représentations métalinguistiques de deux enseignants de DNL (histoire et mathématiques) en français, où il est question de l'agencement délicat des savoirs et des langues dans l'enseignement des DNL, fait émerger le rôle déterminant que jouent celles-ci. Bien que traduisant un hiatus entre traitement linguistique et communicatif chez chacun des enseignants, elles renvoient à des représentations divergentes: une séparation entre langue et discipline chez l'un mais une articulation perceptible pour l'autre, celles-ci s'actualisant dans le discours. Là encore, les cultures associées à deux traditions disciplinaires semblent déterminantes.

$11 \mathrm{Au}$ cœur de l'ouvrage, mais aussi d'un certain effondrement des catégories organisatrices, l'article de Véronique Castellotti et Danièle Moore assure la transition mais aussi la continuïté entre les deux parties. Leur investigation menée dans trois classes diversement situées par rapport aux cultures éducatives dominantes (école bilingue, école plurilingue, école monolingue) fait ressortir les comportements langagiers et les stratégies déployées par les enfants pour accéder à une langue nouvelle inconnue; ceux-ci seraient attribuables à la culture métalinguistique développée et intimement liée aux traditions spécifiques à chacun des contextes. Trois facteurs clé susceptibles de favoriser chez l'apprenant le développement de compétences plurilingues au sens défini dans le Cadre européen commun de référence s'en dégagent: l'expérience plurilingue, la culture métalinguistique et des cultures éducatives prégnantes. Avec ces notions se voient confondre cultures linguistiques et cultures éducatives tout en tissant les liens entre les première et deuxième parties de l'ouvrage.

12 Deuxième partie : « Enseignements/apprentissages des langues et cultures éducatives » 

d'apprentissage scolaires, ou de "cultures éducatives" au sens plus large, qui déterminent les représentations et pratiques d'apprenants (Klingler, Castellotti \& Moore, Suzuki, Dreyer, Bouchard) mais aussi d'enseignants (Klingler, Berthoud, Gajo \& Serra, Cadet et Causa, Suzuki). Le cas d'apprenants d'origines diverses confrontés à une tâche scripturale de résolution de problème (Robert Bouchard) met en lumière la multiplicité des stratégies déployées, celles-ci étant fortement corrélées aux différentes cultures éducatives. Par ailleurs, chez les enseignants en formation (Lucile Cadet \& Maria Causa), il est intéressant de voir qu'au niveau des représentations et les démarches pédagogiques adoptées en stage, les stagiaires ont tendance à s'appuyer spontanément sur des modèles issus de leur culture éducative de scolarisation bien avant d'intégrer des modèles "novateurs " proposés dans le cadre de leur formation. Les habitudes culturelles et éducatives semblent très prégnantes.

Dans certains cas c'est au niveau des relations enseignants-apprenants que s'expriment parfois de véritables conflits interculturels dûs aux contacts de cultures éducatives et sociales éloignées (Elie Suzuki et Serge Dreyer). Ces deux contributions qui portent sur des situations d'enseignement/apprentissage mettant en jeu chez l'enseignant et les élèves, des cultures éloignées non partagées, en l'occurrence le japonais ou le chinois et la culture occidentale, font émerger l'enracinement culturel profond des acteurs en matière de valeurs sociales privilégiées dans les sociétés de référence. Elles constituent un plaidoyer pour la reconnaissance et prise en compte de la différence culturelle, pour une démarche consciente d'enculturation chez les enseignants travaillant avec un public d'une culture éloignée et pour une ouverture à l'altérité comme valeur humaniste universelle fondatrice des relations enseignant-enseigné. 
19 La conclusion (Jean-Claude Beacco et Daniel Véronique) place la didactique des langues et des cultures dans une théorie plus ample du langage et offre au lecteur un retour sur les évolutions de la discipline didactique éclairant l'importance de la notion de situation éducative et la complexification progressive de celle-ci. Elle ouvre sur un débat actuel : celui de savoir la pertinence pour l'avenir d'une didactique des langues, ou d'une didactique du plurilinguisme, trajectoire déjà esquissée dans Billiez (1998 dir.) et intitulé De la didactique des langues à la didactique du plurilinguisme. Hommage à Louise Dabène et qui s'affirme dans Mochet, Castellotti et al. (2005) Plurilinguisme et apprentissages. Mélanges Daniel Coste. Quatre bonnes raisons pour investir dans la lecture de cet ouvrage qui constitue :

- un riche recueil de contributions à la recherche internationale,

- des analyses fines et situées, la mise en oeuvre de méthodologies de recherche variées, novatrices avec leurs spécificités et leur ancrage socio-culturel, le tout assorti de bibliographies riches,

- un ensemble de grand intérêt pour le didacticien désireux de réfléchir à la constitution de son domaine, son épistémologie, ses dimensions historique, ethnographique, socio-culturelle, anthropologique,

Un régal pour pédagogues et enseignants invités à découvrir l'actualité de la classe de langue dans toute sa complexité culturelle.

En guise de conclusion, qu'en est-il de «la didactique des langues face aux cultures éducatives et linguistiques »? Il est amusant d'observer le déplacement qui s'opère progressivement, du colloque (présenté dans son intitulé ci-dessus comme une face-àface, comme une confrontation entre didactique et cultures), à la construction de l'ouvrage (qui prévoit des catégorisations structurantes "cultures linguistiques » et "cultures éducatives» qui accordent la place première d'ailleurs aux cultures linguistiques) et qui finit par un renversement de ces priorités en titrant: "Les cultures éducatives et linguistiques dans l'enseignement des langues "soulignant la primauté cette fois-ci des cultures éducatives. Ce titre, qui mériterait également discussion par rapport au positionnement suggéré par "dans", est emblématique en quelque sorte d'une trajectoire, de l'évolution subtile d'un face-à-face, à une prise de conscience des façons diversement marquantes et qui façonnent d'une certaine manière notre didactique des langues dans ces dimensions immergées et émergentes.

\section{BIBLIOGRAPHIE}

BILLLIEZ, J. (dir.), 1998, De la didactique des langues à la didactique du plurilinguisme. Hommage à Louise Dabène, Grenoble, CDL-LIDILEM.

MOCHET, M-A, BARBOT, M-J., CASTELLOTTI, V., CHISS, J-L, DEVELOTTE, C. \& MOORE, D. (dir.), 2005, Plurilinguisme et apprentissages. Mélanges Daniel Coste, Lyon, École normale supérieure. 
NOTES

1. Le complément des 70 communications est rendu disponible en ligne à sur le site suivant : $<$ marges.linguistiques.com>

\section{AUTEUR}

DIANA-LEE SIMON

Université Stendhal-Grenoble 3, Lidilem. 